\title{
Research Hotspots and Frontiers of Management Innovation at Home and Abroad: Citespace Visual Analysis Based on Literature from 2010 to 2020
}

\author{
Liangcan Liu ${ }^{1}$ Xinyi Wang, ${ }^{2, *}$
}

\author{
${ }^{1}$ School of Business Administration, Guizhou University of Finance and Economics, Guiyang, Guizhou, 550000, \\ China \\ ${ }^{2}$ School of Business Administration, Guizhou University of Finance and Economics, Guiyang, Guizhou, 550000, \\ China \\ *Corresponding author. Email: amywangxinyi@foxmail.com
}

\begin{abstract}
Management innovation has always been a research hotspot in the field of management. Existing companies cannot have sustainable development without innovation in management. In this regard, this article adopts a bibliometric method to review the authoritative journals of management from 2010 to 2020 in the CNKI and WOS database which are analyzed quantitatively. By using citespace software to form a scientific knowledge map, this article analyzes the domestic and foreign research hotspots about management innovation, such as corporate dynamic capabilities, corporate performance, corporate technological innovation, organizational routines, organizational changes, innovation drive, etc., to provide a clear view for the research on management innovation Ideas.
\end{abstract}

Keywords: Management innovation, Measurement visualization analysis, Citespace, CNKI, WOS.

\section{INTRODUCTION}

The development of enterprises is closely related to the prosperity of the country. In the new era, competition between countries is no longer a war of real guns, but more of economic wars, trade wars, and technological wars. The development of domestic enterprises affects the economy, so enterprise management innovation is a serious problem for society. In this rapidly changing world, companies are facing countless challenges. Many entrepreneurs have crossed the river through the dark, relying on their own experience and intuition to break through difficulties one by one, but there are also many companies that die because of wrong decisions. Therefore, paying attention to the research hotspots and frontiers of management innovation is now a top priority.

\section{RESEARCH METHODS AND DATA COLLECTION}

\subsection{Methods}

This research uses the bibliometric software Citespace 5.6 R5, and adopts bibliometric analysis, scientific knowledge map method and prominent word analysis method to analyze the research hotspots and frontiers of management authoritative journals. Bibliometric analysis refers to the quantitative analysis of all knowledge carriers by using mathematical and statistical methods. The main object of quantitative research is literature. Besides, the keyword cooccurrence analysis method can help us get acquainted with the research hotspots of an unknown field, and the scientific knowledge map can reflect the current situation and hotspots of the research field. The prominent word analysis method illustrates the words a appear with a faster rate, reflecting the frontiers of research in this field. Through bibliometric analysis, we can get the fastest and clearest understanding of the 
current research situation, so that we can carry out follow-up research.

\subsection{Data}

The Chinese literature in this study comes from the Chinese Journal Full-text Database (CNKI). In the literature search, we selected authoritative journals, such as : "Management World", "Foreign Economics and Management", "Journal of Management Science", "Southern Management Review", "Management Review" and "Scientific Research Management" , the search time is set to 2010-2020, then manually removing irrelevant content such as meeting records, reports, etc., obtaining 1905 papers, and selected 1802 papers as sample data.

The foreign literature comes from the core collection database of web of science. When searching the literature, we selected journals which are "Academy of Management Journal", "Academy of Management Review", and "Organization Science". The retrieval time is also from 2010 to 2020 . After the topics were screened, a total of 2158 articles were obtained, and 2112 articles were selected as sample data of foreign literature after screening.

\section{RESEARCH HOTSPOTS OF AUTHORITATIVE MANAGEMENT JOURNALS AT HOME AND ABROAD}

This study uses the software Citespace 5.5 R5 to draw a key word co-occurrence knowledge map of the domestic authoritative management journals in enterprise research, as shown in Figure 1:

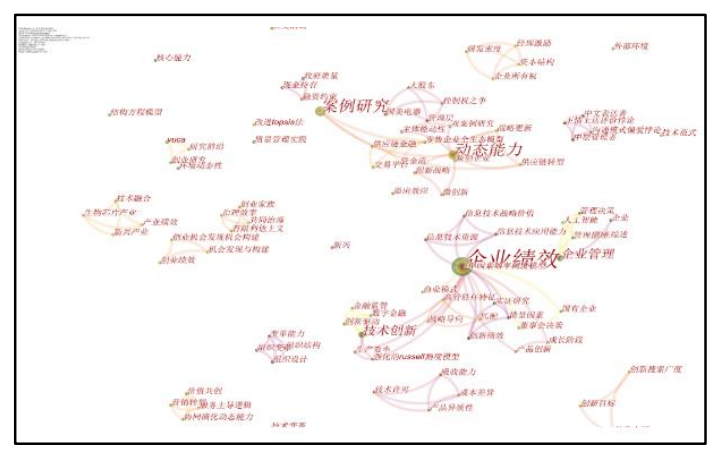

Figure 1 Keyword co-occurrence map of domestic authoritative journals of management in enterprise.

From Figure 1 we can see the keyword network of domestic management innovation, we can know that the key words include case studies, dynamic capabilities, corporate performance, technological innovation, etc., There are another words connecting with them are social responsibility, strategic renewal, new ventures, innovation Strategy, management decision-making, innovation performance, innovation drive and so on, so from Figure 1 we can clearly know the domestic management research hotspots, the following is a brief description of the research hotspots:

\subsection{Corporate Social Responsibility and Technological Innovation}

Some scholars believe that the promotion of corporate social responsibility can promote the technological innovation of enterprises. Social responsibility will become the driving force of enterprise technological innovation, improving enterprises' competitiveness. They believe that when a company wants to establish a good social image, it must improve product quality through technological innovation; when a company wants to actively assume social responsibility, it will maintain technological progress to ensure its good social image. Scholars on the other side don't think so. Li Wenqian and Jia Xingping said that corporate investment in social responsibility will reduce the company's focus on technological innovation activities, thereby increasing the cost of technological innovation [1]. Li Yuanyuan, Li Guihua discoveried that enterprises' social responsibility investment behaviors may consume resources that should be used for technological innovation, thereby forming a hindrance to technological innovation investment [2].

According to Zou Ping's research, when social responsibility investment exceeds the critical value, a "crowding effect" will occur. The reason is that the reduction of technological innovation investment leads to a decline in product quality, which negatively affects the company's reputation. With the increase of corporate social responsibility investment, the promotion of diminishing marginal benefits between corporate social responsibility and technological innovation [6]. With the increase of corporate social responsibility investment, the promotion of diminishing marginal benefits between corporate social responsibility and technological innovation has emerged. This is because, enterprises try to satisfy the demands of stakeholders through corporate social responsibility to obtain certain innovation resources in the initial stage. However, as the intensity of corporate social responsibility investment increases, the resources of innovation investment are gradually occupied and the focus of enterprises on technological innovation dispersed, then the differences in the demands of different stakeholders will increase their innovation risks when weighing the demands of different stakeholders, and enterprises will reduce their investment in technological innovation when taking risk into consideration. In the case of differences in the intensity of corporate social responsibility investment, the impact of technological innovation on brand value presents a positive and then negative inverted U-shaped threshold effect [7]. 


\subsection{Enterprise's Dynamic Capabilities and Innovation Performance}

With the rapid development of society, companies face countless changes every day. In this rapidly changing business environment, it has become more and more difficult for modern enterprises to only rely on existing resources to improve their innovation performance. Improving the dynamic capabilities of enterprises is a necessary measure to deal with the internal and external complex environment. The dynamic capability a high-level capability, including the ability to integrate resources, utilize resources and innovate. This ability evolve into a use capability in cooperation practices. From the keyword co-occurrence map, we can find that dynamic capability is one of the research hotspots of enterprise innovation. Dynamic management capabilities are conducive to improving corporate performance, forming management awareness , managing human capital, and managing social capital all significantly affect corporate innovation performance, which is conducive to promoting corporate innovation performance; business model with the novelty and efficiency can promote the improvement of corporate innovation performance; the dynamic management ability of management can indirectly affect corporate innovation performance through business model design [3]. The current environment is not only the domestic environment, but also the foreign environment. In state-owned enterprises and high-tech intensive enterprises, the high degree of internationalization significantly promotes the increases of dynamic capabilities [8]. Some scholars have studied the relationship between dynamic capabilities and innovation performance of multinational corporations and found that the initial stage of multinational corporations' embedding in global innovation networks. Knowledge exploration and accumulation of local innovation networks are the main factors for the continuous improvement of their innovation dynamic capabilities and innovation performance. In the middle and late stages of multinational corporations embedding in global innovation networks, the level of knowledge internalization of overseas innovation networks is the main reason for the continuous improvement of their innovation dynamic capabilities and innovation performance [9].

\section{ANALYSIS OF RESEARCH HOTSPOTS OF FOREIGN MANAGEMENT CORE JOURNALS}

This study uses the software Citespace 5.5 R5 to draw a key word co-occurrence knowledge map of the research hotspots of foreign management core journals, as shown in Figure 2:

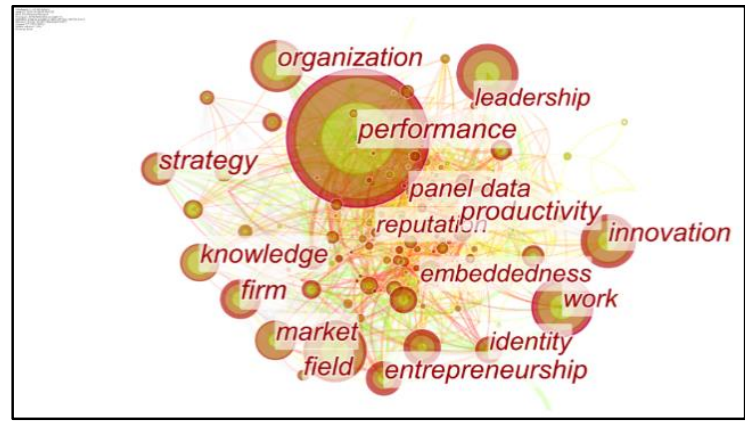

Figure 2 The co-occurrence map of keywords in foreign management journals in management innovation.

From Figure 2 we can see the keyword network of foreign management innovation, we can know that the central words are performance, leadership, innovation, strategy, etc., and connected to data, market, organizational performance, entrepreneur prestige, etc. Below we briefly describe the relationship between entrepreneurship and organizational performance and the relationship between organizational learning and absorptive capacity:

\subsection{Entrepreneurship and Organizational Performance}

In a good institutional environment, entrepreneurs have incentives to innovate on the enterprise's system, management, and technology in order to achieve a more effective allocation of enterprise resources, which significantly enhances the competitive advantage of the enterprise in the market and improves the performance of the enterprise. The research of Covin and Slevin found that enterprises with entrepreneurial spirit can obtain higher market share and profit margins, thereby promoting the growth of corporate performance [4].

\subsection{Organizational Learning and Absorptive Capacity}

Exploratory learning based on absorptive capacity refers to the process of enterprises acquiring external knowledge [5]. Organizational learning is a multi-level concept including individuals, teams and organizations. Organizational learning is based on individual and group-level learning, but it is not a simple superposition of individual and team-level learning results. Through team learning, transforming individual ability into organizational memory, and individual learning is effectively transformed into organizational learning. The complementarity of organizational learning levels is manifested in the transformation of knowledge at three levels, manifested as the transformation between individual knowledge, team knowledge and organization. 


\section{RESEARCH FRONTIERS OF DOMESTIC AND FOREIGN MANAGEMENT AUTHORITATIVE JOURNALS}

What is used here is the prominent word analysis method, which means that if the relative growth rate of a word suddenly increases in a certain short period of time, the frequency change will have a greater degree of transition. We can get the research frontiers of each time period through the increase rate of the word frequency is different from the usual words.

We import the collected and processed data into the software, and then perform prominent word analysis.

Top 6 Keywords with the Strongest Citation Bursts

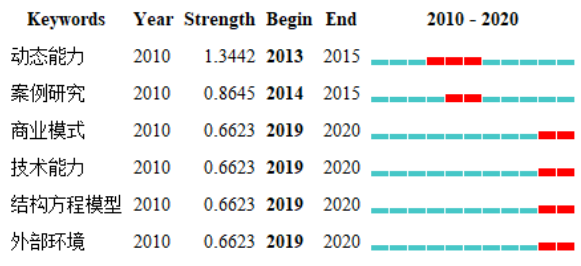

Figure 3 Top 6 highly prominent words in domestic management authoritative journals.

As can be seen from Figure 3, through the analysis of dynamic capabilities, business models, technical capabilities and external environment, we can know the start time and end time of the corresponding research hotspots, as well as the number of years with more frequent occurrences. For example, the frequency of 'dynamic capabilities' started increasing in 2013, then the frequency gradually decreased in 2015. The papers related to dynamic capabilities appeared most frequently during 2013-2015, when was dynamic capabilities' research hotspot.

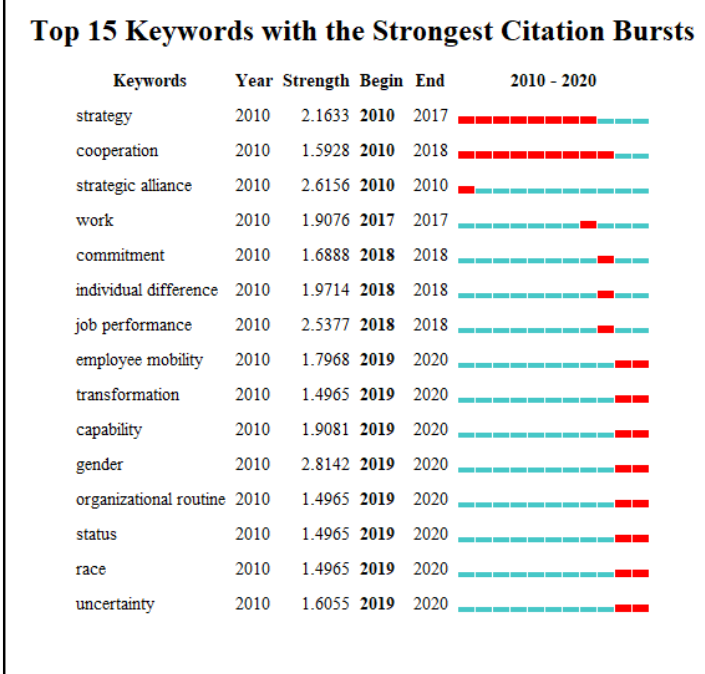

Figure 4 Top 15 highly prominent words in foreign management authoritative journals.
Through the analysis of prominent words of authoritative foreign management journals in Figure 4, we can get the words: strategic alliances, individual differences of employees, job performance, employee mobility, and organizational routines those frequency of occurrence are highest in 2010-2020. We found that organizational conventions appeared less frequently before 2019, and occurred more frequently after 2019 and becoming a hot spot for foreign management innovation research.

\section{CONCLUSION AND SUGGESTION}

Through the quantitative analysis of domestic and foreign management core journals by Citespace 5.5 R5 software, we can come to three conclusions: First, the research hotspots of management innovation at home and abroad include dynamic capabilities, innovation performance, organizational changes, organizational practices, etc.; Secondly, Research in the areas of organizational practice, strategic alliances, and business model innovation has gradually increased in recent years, but there is still a lot of research space in the future; Thirdly, domestic and foreign management innovation researches all present the characteristics of multi-disciplinary cross integration. In addition, in the future management innovation, we should focus on the cultivation of corporate dynamic capabilities to cope with the external complex and changeable environment. How to break through organizational conventions is also a problem that current scholars, entrepreneurs, and managers should think and study. Strategic alliances are also a prevailing and common way of cooperation between enterprises now.How to get the best benefits from alliances is also a question we need to explore.

Today's companies should focus on cultivating dynamic capabilities to deal with the complex problems and challenges which they are about to face; Appropriate corporate social responsibility is conducive to improving the company's reputation and trust, but when the investment in corporate social responsibility exceeds a certain threshold, it will not be beneficial to the technological innovation and product innovation of enterprises; Positive entrepreneurship can improve the performance of organization; Organizational learning should be transformed through organizational absorptive capacity, from the absorption and learning of individual to the absorption and learning of team and then to organizational learning. Therefore, improving the absorptive capacity of enterprises is also the key to enterprise innovation.

\section{ACKNOWLEDGMENTS}

This paper would not have been completed without much assistance, encouragement and support from many people. I want sincerely to avail this opportunity to express my cordial thanks to those who have granted me 
invaluable instructions during the process of thesis writing.

\section{REFERENCES}

[1] Li Wenqian, Jia Xingping, Liao Yonghai, et al. Research on the impact of corporate social responsibility on corporate technological innovation performance under the integration of multiple perspectives [J]. Chinese Journal of Management, 2018, 15(002):237-245. (In Chinese)

[2] Li Yuanyuan, Li Guihua, Zhang Huilong. Corporate Social Responsibility, Technological Innovation and Brand Value [J]. Forum on Science and Technology in China, 2019, No. 275(03):7684. (In Chinese)

[3] Li Kang, Wang Jinfeng, Feng Lijie. The relationship between dynamic management capabilities and corporate innovation performance: the mediating role of business model design [J]. Science and Technology Management Research, 2020, 040(010):174-181. (In Chinese)

[4] Covin J G, Slevin D P. A Conceptual Model of Entrepreneurship as Firm Behavior [J]. Social Science Electronic Publishing, 1991, 16(1).DOI: $10.1177 / 104225879101600102$

[5] Lichtenthaler U. Absorptive Capacity, Environmental Turbulence, and the Complementarity of Organizational Learning Processes [J]. The Academy of Management Journal, 2009, 56(4):1830-1830.DOI: 10.5465/amj.2013.3001

[6] Pang Min. Discussion on the relationship between technological innovation and new product development performance from the perspective of corporate social responsibility [J]. Statistics and Decision, 2015, 000(008):177-179. (In Chinese)

[7] Qi Yongzhi, Li Yuanyuan, Yan Yao. Research on the Threshold Effect of Government Subsidies, Technological Innovation and Brand Value [J]. Macroeconomic Research, 2020, No. 257(04):6272. (In Chinese)

[8] Hai Benlu. Research on Dynamic Capability Performance Mechanism of Internationalized Enterprises [M]. China Economic Publishing House, 2015. (In Chinese)

[9] Sun Hui, Zhang Shuanglan. Research on the relationship between dynamic capabilities and corporate innovation performance in the context of internationalization: empirical evidence from Chinese high-tech companies [J]. Industrial
Technology Economics, 2018, 37(11): 37-45 (In Chinese) 